\title{
大学生创业项目 “聊吧”
}

\author{
任晓玲 郭美杰 张林菲 王迦昕 \\ 太原理工大学现代科技学院 \\ DOI:10.32629/mef.v2i11.370
}

[摘 要] 在这个科技繁荣的时代, 人们对手机的依赖程度越来越高, 低头族现象日趋普遍。为此, 本着放下手机、现实交流的理 念,我们打算建立一个专门的开怀畅聊的场所—— “聊吧” 休闲娱乐厅, 让大家有一个可以拉近距离、直面心灵的放松而又温 馨的环境。无论从多样化的店内设计、具体有效的经营策略,还是从项目开设的餐饮、演艺、树洞、心理治疗等基础及特定 增值服务, 都彰显着本店别具一格的风格特色以及顾客至上的服务宗旨。最终希望能更好地满足各类消费者需求, 进而更稳更 快地开放市场。

[关键词] 大学生; 创业; 聊吧

\section{College Students Entrepreneurship Project "Chat Bar" Ren Xiaoling Guo Meijie Zhang Linfei Wang Jiaxin Polytechnic Institute Taiyuan University of Technology}

[Abstract] In this era of technological prosperity, people's dependence on mobile phones is becoming higher and higher, and the phenomenon of bowing heads is becoming more common. To this end, based on the concept of letting go of mobile phones and realizing communication, we plan to establish a special place for open-hearted chat-"Chat Bar" leisure and entertainment hall, so that everyone have a relaxed and warm environment that can get closer and face the soul. No matter from the diversified store design, specific and effective business strategy, or from the project's establishment of catering, performing arts, tree caves, psychological therapy and other basic and specific value-added services, it has demonstrated the unique style of the store and the customer-oriented service purpose. Ultimately, we hope to better meet the needs of various consumers, and then open the market more steadily and quickly.

[Keywords] college students; entrepreneurship; chat bar

\section{前言}

大学生创业一直是个热门的话题。国家出台许多鼓励大 学生创业的优惠政策, 各大高校也组织学生们参加创业大赛 等活动, 以此提高在校生的创业意识, 丰富学生的课余生活。

在校大学生参加创业项目可以更好的将书本中学的知 识运用在实践中, 以便日后运用知识能更加灵活自如。为不 久的将来步入社会后能更高效地解决工作和生活的问题打 下坚实的基础。

我们作为即将毕业的大四学生, 更应该积极参加大学生 创业活动。在大学生活的这几年, 上课学习专业知识, 课下和 同学相处, 利用业余时间参加社团活动和社会实践活动。增 长了自己的知识, 开阔了眼界, 提升了自己独立思考和解决 问题的能力。当然, 在生活中我们也会发现一些问题, 比如说 人们对手机的依赖程度越来越高, 人们见面后可以聊话题越 来越少, 大家都把精力集中在手机游戏或是手机小说上, 导 致出现无话可聊极度虍尤的场面。

为此, 我们打算建立一个专门的开怀畅聊的场所—— “聊 吧” 休闲娱乐厅, 希望让大家有一个适时放下手机, 敞开心扉, 面对面交流的场所, 有一个有温度的 “垃圾桶” , 以及能共同
营造一个开怀畅聊, 拉近距离, 直面心灵的环境和氛围。

\section{1 创业背景}

1. 1 科技不断的进步, 人们交流方式也发生了很大变化, 手机不离手几乎成了人们的通病, 表面上让大家交流更便 利、更能拉进距离, 实则不然, 心灵之间的距离可能会变得更 加遥远。

1.2 快节奏生活中, 人们压力越来越大, 心理问题越来越 值得重视。有时想要释放压力, 找个倾诉对象, 或想找个纯粹 闲聊的人时, 竟发现通讯录里明明加了数千好友, 却找不到 一个敢聊天的人, 总会担心对方是否愿意当自己的 “垃圾 桶”、会不会浪费人家的时间等种种。大家似乎也仅是朋友 圈的好友而已, 更多时候会把自己包裹起来, 伪装成一副无 所畏惧的样子。

\section{2 创业目的}

2. 1在大学生活中, 我们不过是 “纸上谈兵”, 而当今社会 需要的是经验, 我们需要把在学校学到的知识投入到实践去。

2.2 在这个竞争激烈的社会, 我们即将面临毕业, 就业难 的环境让我们无法在这个紧张的社会中发挥自己的实力, 我 们需要创业平台展现我们的才华。 


\section{3 经营项目及内容}

3. 1经营内容: 主要目的是为了让现在的人们放下手机, 多关心关心身边的亲人, 恋人, 以及朋友。同时达到促进亲朋 好友之间的联络, 达到真正的感情去交流。

3.2 主要项目: (1) 基础服务: 餐饮服务。一部分是顾客 自己点的餐饮, 另外一部分是每个客户类型送的免费的小套 餐。（2) 演艺服务和公共娱乐设施服务：我们会定期提供一 些公演的小活动, 使顾客可以在本店放松心态, 玩的尽兴。公 共设施可以提供顾客随意玩。(3) 树洞服务: 这是我们去的 增值服务, 我们为顾客提供一个比较暗的房间里, 顾客和我 们的专业 “树洞” 诉说自己的烦恼, 和心里话。提供 “只进 不出” 的树洞服务, 使顾客可以尽情倾诉。(4) 匿名陪聊: 有 些顾客可能在现实生活中, 缺少真心朋友, 没有人可以说心 里话, 或者内心缺乏爱和安全感, 可以选择此项服务, 在保证 顾客所有信息均不透明的环境下 (通过变声话筒、隔板等方 式), 提供陪聊服务, 解开消费者心结。我们的陪聊人员也会给 予顾客最真诚的温暖。(5) 心理咨询服务: 由于很多人会对心 理治疗心怀恐惧, 有所抗拒, 可以在此聘请专业的心里治疗师 提供心理治疗服务, 在这样一个相对轻松的环境中, 消费者可 以消除心中芥蒂, 与心理咨询师有效沟通。(6)制订特殊服务: 针对不同聊天群体提供不同专属服务, 对亲人、朋友、同事、 恋人等之间出现的不同问题提供调解及讲和服务。

\section{4 服务原则}

4.1 以独特的环境和模式为顾客提供服务。

4. 2 注重顾客的感受, 尽最大努力满足顾客的需求。

\section{5 服务群体}

聊吧面向所有想要与朋友们脱离手机面对面交流情感 的人们, 以及需要在殹意的环境中进行业务沟通的人们。聊 吧核心服务主要是为 90 后、 00 后的 “低头族” 提供一个没有 手机的干扰的谈心、放松的场所。

\section{6 市场分析}

6. 1 当下 90 后和 00 后的年轻人几乎是在网络科技繁荣的 时代中成长起来的, 手机越来越智能, 功能渐渐全面, 使得人 们可以在手机上完成购物, 订餐, 阅读书刊、新闻, 网上聊天 等事情, 科技发达带来的好处冊庸置疑, 但是也出现了一些 弊端, 那就是人们即使没事的时候也都会低头看手机刷小视 频等娱乐性的信息。手机占据了人们 $50 \%$ 的时间, 人与人之间 的交流渐渐地减少, 导致现实生活中会出现人们见了面后都 在看手机, 沉浸在自己的世界里。

6.2 有许多职场人员需要和客户洽谈业务经常选择去饭 店在酒桌上谈生意, 有时并非人们愿意去饭店和客户沟通, 而是本着想在一个放松舒适的环境中拉进和客户的距离。对 于长期需要和客户洽谈的人员的健康造成一定的影响。而聊 吧有各种风格的小雅间供顾客选择, 安静、舒适是我们的特 色, 聊吧还提供各式各样的茶饮, 糕点, 水果, 所有的食品绝
对绿色健康, 物美价廉。对于有业务沟通的职场人员, 聊吧是 个不错的选择。

人力上: 集纳高思维、有独特创新思想的人才进入; 同 时, 我们需要召集一些专业的心理师和培训一批有耐心, 有 爱心, 有想法的人才。

宣传上: 我们将会大量印发宣传单, 在各大商业圈分发, 我们还将在 “抖音”、“快手”、“微博”、各大公众号合作, 一展本店的风采。

经营上: 开业初期, 我们将采取前50名顾客进店免费的 服务以及配合老顾客带新顾客打折的优惠政策来增加我们 的客流量和知名度。中期采取集赞的活动享受折扣的方案来 吸引新老顾客。

店面上：店面设在客流量多的商业区, 店面设计新颖, 特殊。

\section{7 经费分配}

选址: 首先我们在客流量较大的商业区选择店面。装修 及采购所需物品: 聊吧主要分为两个区域, 畅聊区和畅玩区。 畅聊区装修成一个个小雅间, 雅间的风格也大不相同, 有简 约风格, 甜美风格, 浪漫风格等。畅玩区设置多种游戏娱乐设 施供顾客们娱乐。

雇佣员工：店内需要一名前台, 两名服务员。

宣传推广: 新店开业。

\section{8 收费标准}

基础服务: 将按照正常市面价格收费, 不会按照高端餐 厅一样的高价格去定价。

增值服务：根据不同服务的价格收费。

演艺服务: 按 20 元/小时收费。树洞服务: 80 元/次 (一 次最长 3 小时)。

匿名陪聊服务: 20 元/小时。(不够一小时均按15元收费)。

心理咨询服务: 100元/一次。特殊制订服务: 制订一次 专属服务为 99 元/次, 其他费用根据以上收费标准收取。

\section{9 预想问题及解决方案}

问题：初期折扣力度大, 出现资金不足的现象。

解决方案：拉一些赞助商和合作伙伴, 在本店消费送合 作商和赞助商的消费券, 达成合作共赢的目的。

\section{[参考文献]}

[1]崔心愉.关于大学生创业项目的研究——基于大学生 餐饮服务行业创业实践调查[J].科技经济导刊,2017(18):240.

[2]耿胥, 黄婕, 邓自洋. 高校 “大学生创新创业训练计划” 项 目管理模式的探索与实践[J].化工高等教育,2017,34(5):43-47.

\section{作者简介:}

任晓玲 (1989--),女,山西省晋中市人, 汉族, 硕士, 研究方 向: 企业管理。

郭美杰(1996--),女,山西省原平市人,汉族,2019 级会计 学专业本科在读。 